\title{
LEITURA E PRODUÇÃO DE TEXTO NA FORMAÇÃO CONTINUADA DE PROFESSORES ALFABETIZADORES
}

\author{
RENATA JUNQUEIRA DE SOUZA \\ Doutora em Letras pela Universidade Estadual Paulista Júlio de Mesquita Filho. Professora visitante da Universidade \\ do Minho. Professora assistente da Universidade Estadual Paulista Júlia de Mesquita Filho. Professora colaboradora no \\ Programa de Pós-Graduação em Letras da Universidade Federal do Espírito Santo (UFES). E-mail: recellij@ gmail.com \\ GISLENE APARECIDA DA SILVA BARBOSA \\ Mestra em Educação pela Universidade Estadual Paulista Júlio de Mesquita Filho. Professora da Faculdade de \\ Presidente Prudente e de Educação Básica na Escola Estadual Professor Arlindo Fantini. \\ E-mail: barbosagislene@gmail.com
}

\section{RESUMO}

Este artigo apresenta um relato de experiência sustentado nas ações desenvolvidas, em 2013, no Pacto Nacional pela Alfabetização na Idade Certa - PNAIC, realizado no polo de Presidente Prudente/SP, pela Universidade Estadual Paulista Julio de Mesquita Filho (UNESP), em parceria com o Ministério da Educação e Cultura. O PNAIC é um programa de formação continuada de professores com o objetivo de redirecionar as ações da escola básica ( $1^{\circ}, 2^{\circ}$ e $3^{\circ}$ anos), a fim de que todos os alunos estejam alfabetizados até os 8 anos de idade. O polo de formação em Presidente Prudente realizou, com professores de 67 municípios paulistas, estudos e orientações sobre o processo de ensino e de aprendizagem da leitura e da produção de texto pelo uso, respectivamente, das Estratégias de Leitura (GIROTTO e SOUZA, 2010) e da Sequência Didática (DOLZ, NOVERRAZ e SCHNEUWLY, 2004). Ambos os procedimentos organizam, sistematicamente, atividades escolares que permitem ao professor planejar etapa por etapa de atuação pedagógica e permitem ao aluno compreender as minúcias que envolvem o processo de ler e de produzir textos. $\mathrm{O}$ processo formativo de professores durante o curso de Língua Portuguesa visou ao desenvolvimento de capacidades nos docentes, os quais foram compreendidos como sujeitos essenciais para a melhoria do processo de alfabetização nas escolas. O objetivo do relato é o de socializar as ações formativas realizadas pelos orientadores de estudo com os professores alfabetizadores, sobre estratégias de leitura e sequência didática, destacando o desenvolvimento de projetos de práticas de leitura e produção textual, desenvolvidos com alunos de $1^{\circ}$ ao $3^{\circ}$ ano do Ensino Fundamental, de escolas públicas de Presidente Prudente/SP.

Palavras-chave: Estratégias de leitura. Sequência didática. Formação continuada.

\section{READING AND WRITING IN LITERACY TEACHERS' CONTINUING EDUCATION}

\begin{abstract}
This paper presents an experience report of actions taken in 2013, the National Pact for Literacy at Age One - PNAIC held in Presidente Prudente / SP, Universidade Estadual Paulista Julio de Mesquita Filho (UNESP) and the Ministry of Education and Culture. PNAIC is a program for continuing education for teachers in order to improve the activities of basic school (1st, 2nd and 3rd year), so that all students are literate by the age of 8 . The course held in Presidente Prudente, with teachers from 67 counties, studies and guidelines on the teaching and learning of reading and text production for use, respectively, of Reading Strategies (Girotto and SOUZA, 2010) and Didactic Sequence (DOLZ, NOVERRAZ and SCHNEUWLY, 2004). Both procedures allow the teacher to plan step by step and pedagogical activities allow students to understand the details involved in the process of reading and producing texts. The Portuguese course aimed at developing capacity in teachers, subjects understood as essential to improving the literacy process in schools. The objective of the report is to socialize the training activities carried out by guiding study with literacy teachers
\end{abstract}


on reading strategies and didactic sequence, highlighting the development projects of reading practices and textual production, developed with 1 to 3rd year students of elementary school, in public schools in Presidente Prudente / SP.

Keywords: Reading strategies. Didactic sequence. Continuing education.

\section{Introdução}

O Ministério da Educação e Cultura (MEC), em parceria com universidades públicas brasileiras, iniciou, em 2013, uma ação de formação continuada para professores alfabetizadores de todo país, intitulada "Pacto Nacional pela Alfabetização na Idade Certa" (PNAIC). Tal medida está relacionada aos baixos índices de desenvolvimento da alfabetização nos alunos de até 8 anos de idade, constatados por pesquisas e dados do MEC.

No Estado de São Paulo, uma das universidades envolvidas no PNAIC é a Universidade Estadual Paulista Julio de Mesquita Filho (UNESP), que organizou a formação em diferentes polos. O relato presente neste texto diz respeito às atividades desenvolvidas no polo da UNESP Faculdade de Ciências e Tecnologia (FCT) de Presidente Prudente.

O PNAIC, de acordo com informações disponíveis no site do programa, é um "compromisso formal" assumido pelos governos federal, estadual e municipal para assegurar que todas as crianças até 8 anos de idade estejam alfabetizadas ao final do $3^{\circ}$ ano do ensino fundamental (em Língua Portuguesa e em Matemática). No PNAIC, existem 4 eixos de atuação: 1. Formação continuada presencial para os professores; 2. Oferta de materiais didáticos para as escolas; 3. Aplicação de avaliações sistemáticas para acompanhar a aprendizagem das crianças; 4. Gestão, mobilização e controle social do programa.

Em 2013, o polo da UNESP de Presidente Prudente, composto por 2 supervisoras e 5 formadores, atuou no eixo da formação continuada, ministrando um curso de Língua Portuguesa a 67 municípios paulistas, representados por orientadores de estudo. Os orientadores de estudo são professores alfabetizadores que participam da formação presencial em Presidente Prudente e depois ministram o curso em suas localidades, alcançando juntos, aproximadamente, 1600 professores alfabetizadores, atuantes nos três primeiros anos do ensino fundamental dos municípios envolvidos.

No total, em 2013, foram realizadas 136 horas de estudos presenciais para os orientadores (5 encontros), em Presidente Prudente. Nestes encontros, os orientadores de estudo receberam formação para que ministrassem, em seus respectivos municípios, um curso com 80 horas de duração, distribuído em 10 dias, de abril a dezembro.

O curso de Língua Portuguesa, realizado em 2013, tratou de diversos temas relacionados à linguagem, organizando-os nos eixos de oralidade, leitura, produção de texto e análise linguística. 
Para este relato, serão apresentadas duas ações desenvolvidas no polo de Presidente Prudente, com os orientadores de estudo, de março a novembro de 2013, com relação ao eixo da leitura e ao eixo da produção de texto, respectivamente, pelo uso das Estratégias de Leitura e da Sequência Didática. As práticas aqui apresentadas também foram realizadas pelos orientadores de estudo com professores alfabetizadores de escolas públicas vinculadas, por suas secretarias de educação, ao PNAIC.

\section{PNAIC em Presidente Prudente: apresentação das ações}

As ações formativas realizadas no polo de Presidente Prudente envolviam aulas, oficinas e palestras acerca dos processos de ensino e de aprendizagem da língua materna. A definição dos assuntos seguia a programação geral do PNAIC, que apresenta um material de formação, no qual estão propostos os seguintes temas para estudo dos professores alfabetizadores: 1. Concepções de alfabetização e currículo; 2. Planejamento do ensino da alfabetização e uso de diversos recursos didáticos; 3. O funcionamento do sistema de escrita alfabética; 4. A sala de aula como ambiente alfabetizador, o uso de jogos no ensino; 5. Os diferentes textos nas aulas de alfabetização; 6 . Projetos Didáticos e Sequências Didáticas na alfabetização; 7. Avaliação e planejamento das atividades a serviço da inclusão dos alunos que estão com mais dificuldades de aprendizagem; 8. Avaliação final, registro das aprendizagens e organização dos arquivos para uso na sala de aula.

Assim, o curso de Língua Portuguesa do PNAIC aconteceu com o apoio de material disponibilizado pelo MEC aos professores alfabetizadores, organizado em 4 tipos de publicação, cada uma voltada a um dos respectivos grupos de alfabetizadores:

- Cadernos do Ano 1 - com 8 unidades para estudos dos professores que lecionam para o $1^{\circ}$ ano;

- Cadernos do Ano 2 - com 8 unidades para estudos dos professores que lecionam para o $2^{\circ}$ ano;

- Cadernos do Ano 3 - com 8 unidades para estudos dos professores que lecionam para o $3^{\circ}$ ano;

- Cadernos de Educação no Campo - com 8 unidades para estudos dos professores que lecionam para turmas multisseriadas $\left(1^{\circ}, 2^{\circ}\right.$ e $3^{\circ}$ anos $)$, em área rural.

Embora separados por ano de escolaridade, os temas tratados em cada unidade são afins entre os materiais, variando o nível de profundidade do tema e apresentando sugestões de atividades adaptadas à idade dos alunos e nível de conhecimento da escrita convencional. Por exemplo, o tema da unidade 6 de todos os cadernos é: O trabalho com Projetos e com Sequências Didáticas. Para o 
ano 1, as discussões contemplam reflexões sobre o sistema de escrita alfabética, enquanto no ano 3 , tratam de consolidações sobre a os aspectos linguísticos que envolvem os textos mais complexos, como a estruturação de uma história em quadrinhos.

Além dos Cadernos com as unidades de estudo para os professores, o PNAIC apresenta também o Caderno de Formação; o Caderno de Educação Especial; o Caderno de Apresentação e o Caderno de Avaliação.

\section{Produção de Texto no PNAIC}

Na unidade 6 de cada Caderno voltado ao professor dos anos iniciais, há ênfase no processo de produção textual nos anos iniciais do ensino fundamental. Desde o Caderno de Apresentação do PNAIC (Brasil, 2012, p. 31), existe a afirmação de que um dos objetivos do curso de Língua Portuguesa é: "Analisar e planejar projetos didáticos e sequências didáticas para turmas de alfabetização". Esta ação é trazida em pauta na unidade 6, quando os professores irão refletir sobre o ensino sistemático da produção de texto, com o apoio da Sequência Didática.

A produção de texto, segundo os materiais do PNAIC, deve habitar as salas de aula, desde os anos iniciais, pois contempla o processo de reflexão do aluno sobre a organização textual e serve como indicador aos professores de como os estudantes se apropriam das mais variadas formas de semiotização da língua.

No Caderno de Avaliação (Brasil, 2012, p. 30), está a afirmativa de que a produção de texto desde o primeiro ano do ensino fundamental é importante, pois, ao ler o texto produzido pelo aluno, "o professor pode perceber o modo como os alunos compreenderam as situações de ensino que os levaram a escrever de determinado modo, os conhecimentos que possuem diante do gênero e da temática proposta, entre outros aspectos".

Na mesma unidade 6 dos Cadernos para os professores, existe a indicação do procedimento Sequência Didática como facilitador do trabalho docente de ensinar a produzir texto. Diante dessa abordagem escolhida pelos materiais, o polo de Presidente Prudente, ao trabalhar com as unidades 6, optou por complementar as ações com um estudo sistematizado da teoria da Sequência Didática, dos autores genebrinos Dolz, Noverraz e Schneuwly (2004).

Para isso, foram desencadeadas as seguintes ações: 1. Os orientadores de estudo receberam com antecedência um e-mail no qual eram convidados a ler a obra que trata da Sequência Didática. 2. Durante o encontro presencial, os orientadores de estudo releram trechos da obra, socializaram as aprendizagens que tinham construído ao longo das leituras e das práticas de trabalho nas escolas, estudaram os principais conceitos e as etapas da Sequência Didática. 3. Ainda durante o encontro, 
puderam também construir, com a ajuda do formador responsável, um exemplo de Sequência Didática com o gênero textual tirinha. 4. Por último, estudaram o material do PNAIC, que apresenta outros exemplos de Sequência Didática e debateram sobre as principais dificuldades de realização de uma Sequência Didática na escola, também propuseram maneiras de como incentivar os professores na aplicação de Sequências Didáticas.

Para que fique evidente o conceito de Sequência Didática trabalhado no encontro presencial, cabe apresentar uma rápida síntese do mesmo:

De acordo com Dolz, Noverraz e Schneuwly (2004), a Sequência Didática tem a finalidade de ajudar o aluno a dominar melhor um gênero de texto, permitindo-lhe, assim, escrever, ler ou falar de uma maneira mais adequada numa dada situação comunicativa. Ela decompõe as atividades comunicativas complexas, que os estudantes ainda não são capazes de produzir sozinhos, para que possam estudar, um a um, os componentes que se mostrarem como obstáculos à aprendizagem e à realização do gênero discursivo. Funciona como instrumento de orientação ao trabalho docente, sistematizando o ensino.

Dolz, Noverraz e Schneuwly (2004, p. 98) desenvolveram um esquema para representar as etapas que compõem uma Sequência Didática: apresentação da situação; produção inicial; módulos; produção final.

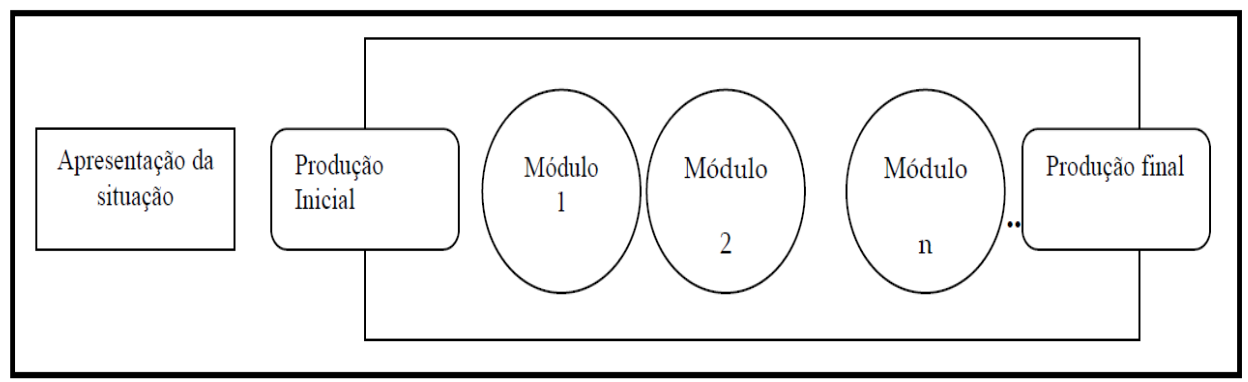

Figura 1 - Esquema da Sequência Didática, elaborado por Dolz, Noverraz e Schneuwly (2004, p. 98)

A apresentação da situação é a etapa de expor "aos alunos um projeto de comunicação que será realizado verdadeiramente na produção final" (p. 99). Essa etapa requer, ainda, a apresentação de "um problema de comunicação bem definido" (p. 99) e a preparação dos "conteúdos dos textos que serão produzidos” (p. 100). Respectivamente, é necessário definir o gênero discursivo a ser trabalhado, o destinatário, a forma que a produção assumirá (vídeo, impresso etc), quem participará do projeto; depois é necessário que os alunos saibam com quais conteúdos vão trabalhar e a importância desses conteúdos no texto em produção. 
A etapa produção inicial é o momento de os alunos colocarem em evidência, para si mesmos e para o professor, o que sabem sobre o gênero discursivo selecionado para estudo. Na produção inicial, nos dizeres dos autores mencionados, o docente tem a oportunidade de "realização prática de uma avaliação formativa" (p. 102), porque a produção de texto evidenciará o que cada estudante sabe.

Na etapa módulos, o professor trabalha, separadamente, com os problemas que apareceram na primeira produção, ou seja, decompõe o gênero discursivo para abordar problemas de níveis diferentes, tais como a representação da situação comunicativa (a fim de focalizar o destinatário, ter clareza da finalidade da produção textual, saber seu papel como interlocutor e saber a função que o gênero discursivo selecionado exerce socialmente); a elaboração dos conteúdos (buscar, elaborar ou criar conteúdos de acordo com a especificidade de cada gênero); o planejamento do texto (manter certa padronização da estrutura composicional do gênero discursivo em foco); a realização do texto (escolher o vocabulário adequado, usar bem os verbos, trabalhar com os argumentos etc).

A última etapa é a produção final, a qual oportuniza ao aluno colocar em prática o que aprendeu ao longo dos módulos, ter consciência de seu próprio processo de aprendizagem e trabalhar como regulador de seu próprio comportamento na revisão e reescrita do texto que circulará socialmente.

A produção final também serve como avaliação somativa para uso do professor, o qual pode corrigir o texto com o apoio de uma grade que expõe os elementos necessários ao desenvolvimento do gênero discursivo, os critérios de correção e a nota atribuída a cada item. Com a grade, o docente tem uma visão sistemática das aprendizagens dos alunos; assim, fica mais acessível ao educador a retomada de itens não apreendidos pelos estudantes.

Diante das etapas expostas, é possível perceber que a Sequência Didática é uma oportunidade de sistematizar o ensino, portanto ela tende a acrescentar muito na qualidade formativa dos alunos, pois é didaticamente organizada para fazer o estudante pensar em cada etapa de elaboração de um gênero discursivo, reconhecendo a situação comunicativa; a forma, o estilo e o conteúdo do texto em construção; estudando aspectos linguísticos e extralinguísticos que colaboram na construção textual.

Com base nestas concepções teóricas, os orientadores de estudo puderam entender que a "redação tema livre" não ajuda no desenvolvimento e conhecimento dos alunos sobre o gênero, pois quando há proposta de escrever uma história qualquer, sem função social definida, falta "modelo" de texto, falta também a definição de como os elementos linguísticos serão usados, já que o gênero, 
em seu estilo, apresenta uma maneira particular de uso de recursos como verbos, pontuação, organização dos períodos etc.

O trabalho escolar, no domínio da produção de linguagem, faz-se sobre os gêneros, quer se queira ou não. Eles constituem o instrumento de mediação de toda estratégia de ensino e o material de trabalho, necessário e inesgotável, para o ensino da textualidade (DOLZ et al, p. 51).

Outro aspecto refletivo a partir do estudo da Sequência Didática foi a relevância da produção de texto desde o $1^{\circ}$ ano do Ensino Fundamental, uma vez que o ensino contextualizado da alfabetização requer o uso de textos reais e, considerando as características dos gêneros textuais envolvidos, as crianças já conseguem reconhecer, pelo uso social, a estrutura (forma composicional) dos textos, a função social dos textos etc.

No processo de estudo com os orientadores, uma Sequência Didática com base no gênero tirinha foi construída, pois era necessário superar a dicotomia teoria-prática. Desta forma, a elaboração de uma Sequência Didática serviria para aproximar o professor do procedimento metodológico.

Considerando que a tarefa da escola é ensinar o aluno a fazer uso da leitura e da escrita em práticas sociais, em contextos específicos, para objetivos específicos (KLEIMAN, 2004, p. 19), é necessário ensinar aos alunos os comportamentos escritores, os quais envolvem as ações de planejar o que se pretende escrever; textualizar, isto é, escrever o texto propriamente dito; e revisar o texto escrito.

Para a etapa da apresentação da situação, algumas perguntas foram construídas para ajudar no planejamento da escrita: Que gênero textual será produzido? Quem lerá o texto produzido? Qual será o tema do texto? Qual a função social deste gênero? Quem costuma produzir este gênero? Por onde este gênero circula? Que linguagem é usada por este gênero? Que forma assumirá a produção final? Onde será publicada a produção final?

Depois de definir também as respostas para os questionamentos elencados anteriormente, era preciso preparar os conteúdos dos textos a serem produzidos, portanto os orientadores de estudo levantaram a necessidade de oferecer aos alunos fontes confiáveis de pesquisa.

Nesse momento, os orientadores de estudo refletiram sobre a importância de oferecer bons "modelos" do gênero para o aluno, ou seja, de realizar algumas atividades de leitura e interpretação com exemplares do gênero, fazendo o aluno conhecer o gênero ao ter mais contato com ele no ato da leitura. Assim, o grupo de orientadores de estudo chegou à conclusão de que, na sala de aula, é importante explorar, com os alunos, tirinhas diversas, para que eles conheçam recursos e características do gênero (linguagem verbal e não verbal; situação inicial- conflito - resolução 
(quebra de expectativa); uso dos balões; local de circulação, autores, temas comuns às tirinhas, etc. (Elaborar perguntas para que os alunos pensem/interpretem o texto lido)

Em seguida, entre os orientadores de estudo, aconteceu uma reflexão sobre a escrita da $1^{\text {a }}$ versão do texto dos alunos (primeira produção). Para os autores Dolz, Noverraz e Schneuwly (2004), esse é o momento em que os alunos colocam em evidência, para si mesmos e para o professor, o que sabem sobre o gênero oral ou escrito selecionado para o trabalho pedagógico. A partir do que cada aluno produz, o professor consegue perceber as capacidades que os alunos já desenvolveram; então, pode fazer intervenções que promovam o desenvolvimento das potencialidades dos estudantes. Para o docente, a primeira produção é também a "realização prática de uma avaliação formativa" (p.102), pois não visa à atribuição de nota, mas sim ao momento rico de obtenção de informações sobre o que cada aluno sabe. Para o estudante, o momento da primeira produção já é o "primeiro lugar da aprendizagem" (p.103), porque, o fato de produzir o texto, o leva a pensar nas dificuldades de elaboração, nas capacidades desenvolvidas em si mesmo, nos exemplares do gênero textual que ele conhece etc.

Foi neste contexto que surgiu uma inquietação no grupo de orientadores de estudo: o que fazer com os alunos não alfabéticos? Após uma conversa coletiva, a conclusão foi a necessidade de ajuda de um escriba, que poderia ser o professor ou amigo da turma, portanto, concluiu-se que a escrita coletiva é uma boa estratégia, no caso de turmas não alfabéticas. Para isso, a lousa poderia ser um recurso bem utilizado, já que facilitaria a visualização de todos os estudantes.

$\mathrm{Na}$ construção de atividades que serviriam para a etapa dos módulos, os orientadores de estudo tentaram resgatar as principais dificuldades que os alunos de $1^{\circ}, 2^{\circ}$ e $3^{\circ}$ ano apresentam no ato da escrita de um texto. Dessa forma, consideraram que atividades de observação e de análise de textos ajudam a perceber a organização dos textos e a construção do sentido, assim sugeriram: comparação de tirinhas para levantar os diferentes temas; análise de tirinhas para identificar a apresentação da situação, conflito e resolução; a diferença entre balões da fala, de pensamento, de grito; a forma das letras como recurso expressivo; a expressão das personagens; o uso da pontuação etc.

Consideraram também que as tarefas simplificadas de produção de texto ajudam na organização textual e facilitam o domínio gradativo do aluno sobre um gênero de texto, portanto os orientadores de estudo pensaram em atividades de organizar as falas dentro de um balão; inserir uma parte que falta no texto - seja na imagem ou no texto verbal; usar a letra maiúscula ou minúscula, conforme a necessidade; utilizar adequadamente a pontuação, diminuir número de quadrinhos para atender à forma do gênero; reescrever trechos repetitivos, substituindo a repetição 
por pronomes ou expressões equivalentes; completar balões com supostas falas, de acordo com a expressão fisionômica das personagens etc.

Ainda nos módulos, os orientadores pensaram sobre atividades que favorecem a elaboração de uma linguagem comum para poder falar dos textos, comentá-los, criticá-los, melhorá-los. Chegou-se à constatação que é importante questionar os alunos sobre os aspectos que não podem faltar na elaboração do gênero, no caso, a tirinha. Perguntas como "O que colocamos no primeiro quadrinho?" ajudam na construção do reconhecimento do gênero.

Para a etapa da produção final, os orientadores levantaram alguns elementos que seriam importantes na elaboração da grade de correção do texto produzido pelos alunos: A forma composicional do gênero foi garantida? O conteúdo temático previsto foi desenvolvido (de modo geral)? A linguagem utilizada levou em conta o leitor pretendido e o local de publicação/circulação do texto? O texto apresenta sentido (coerência)? Existe uso adequado da narrativa? A ilustração dialoga bem com o texto verbal? O vocabulário usado está adequado? Existe uso adequado de pronomes ou sinônimos para retomar ou substituir ideias no texto? A pontuação está adequada? A grafia das palavras está adequada?

Depois disso, os orientadores de estudo regressaram para seus municípios e trabalharam com a unidade 6 dos Cadernos do PNAIC, que trata da Sequência Didática.

Quando regressaram a Presidente Prudente, iniciaram relatos de que a receptividade entre os professores nas localidades foi muito grande, porque a maioria deles desejou elaborar uma Sequência Didática como tarefa da unidade 6, a fim de aplicar com os alunos em sala de aula. Para os orientadores de estudo, a Sequência Didática ofereceu algo que os professores alfabetizadores esperavam há muito tempo: uma sistematização do trabalho com a produção de texto, capaz de integrar o ensino da análise linguística a serviço da construção do sentido do texto.

Nos relatórios escritos, os orientadores de estudo destacaram a grande contribuição da Sequência Didática na compreensão de que a escrita na escola deve ter vínculo com a prática social e deve se sustentar na produção de um gênero.

Além disso, as etapas da Sequência Didática trouxeram clareza aos professores sobre como agir com os alunos, ou seja, priorizar um aspecto de cada vez, tendo em conta o elemento maior que é o gênero textual em foco. O uso da grade de correção confere maior segurança ao docente que pode se atentar aos elementos de coerência textual e não apenas questões ortográficas.

Em diversos municípios, os alfabetizadores puderam aplicar uma Sequência Didática com alunos do ensino fundamental. Segundo relato dos orientadores de estudo, as crianças conseguiram 
entender as etapas do trabalho e realizaram a produção final com significativas melhoras em relação à produção inicial de gêneros textuais como: carta, tirinha, bilhete e conto.

Apesar de ter sido o primeiro contato de grande parte do grupo de orientadores de estudo e professores alfabetizadores com a Sequência Didática, a aceitação foi grande e os pedidos por mais estudos sobre o tema apareceram nas avaliações finais do curso de 2013.

Em um município pequeno do interior paulista, distante $60 \mathrm{~km}$ de Presidente Prudente, a professora do $3^{\circ}$ ano, formada em Letras e em Pedagogia, elaborou uma Sequência Didática para seus alunos, para estudar com eles o gênero fábula. Ela relatou que não tinha conseguido, até então, sistematizar o ensino da produção de texto nas aulas, pois, em geral, os alunos escreviam um texto e entregavam para ela corrigir. Ela fazia as correções, indicando para os alunos o que estava errado (escrevia no canto da página do caderno dos estudantes) e eles passavam a limpo o texto no caderno de produção textual. A docente afirmou que não estava satisfeita com tal prática, porque percebia que muitos alunos "passavam a limpo" as anotações que ela fazia, portanto os resultados de melhoria na produção textual eram pequenos.

Quando estudou, no PNAIC, o procedimento Sequência Didática, compreendeu que os textos devem circular socialmente, que as dificuldades dos alunos são objetos de estudo durante os módulos e que a reescrita deve ser feita a partir das reflexões dos estudantes. Assim, preparou a leitura de 3 fábulas (A cigarra e a formiga, O lobo e o cordeiro, O cachorro e o reflexo), fez atividade de interpretação e propôs uma produção de texto: escrever uma fábula, para os colegas do $4^{\circ}$ ano, com a temática escolhida pelas crianças - "verdadeira amizade". Com base nos resultados, elaborou os módulos, com destaque para: organização dos parágrafos; separação das atuações do narrador e fala das personagens (discurso direto/ discurso indireto); substituição pelo uso de pronomes e por elipse; uso do verbo no pretérito perfeito, no pretérito imperfeito e no presente; sequência da narrativa e construção de lógica interna no texto (coerência). Tendo feito atividades com o apoio de materiais didáticos disponíveis na escola, a professora organizou os alunos para ações em duplas e percebeu que, em alguns momentos, como no uso do discurso direto, funcionaram bem as atividades coletivas, com a atuação da professora como escriba, na lousa. Os alunos, depois da produção final, enviaram os textos para a leitura dos colegas de outra turma. A professora declarou que a produção final trouxe muitas conquistas das crianças na produção, especialmente quando ao uso dos discursos, organização lógica do texto e uso de pronomes. A atividade durou 2 semanas, com aulas diárias que duravam, em média, 2 horas.

\section{Leitura no PNAIC}


Na unidade 5 de cada Caderno, há ênfase ao uso dos gêneros textuais nos anos iniciais do ensino fundamental, para que o processo de alfabetização aconteça vinculado às práticas sociais reais, na perspectiva do Letramento (Soares, 2002).

Mais do que ser capaz de decodificar elementos gráficos, o cidadão do presente século tem de ser capaz de interagir com a língua, utilizando a linguagem para o sucesso nas relações sociais, sendo capaz também de se expressar bem, ouvir o outro e utilizar o conhecimento de mundo e o da organização dos textos para compreender as distintas situações a que se expõe e interagir com elas, construindo sentidos e ressignificando a vida.

Saber ler e escrever deixa, portanto, de se referir apenas ao domínio do código e passa a se referir à necessidade do desenvolvimento de um estado ou condição, no qual o indivíduo assuma a postura de interlocutor e participe ativamente das diversas práticas de leitura e escrita na sociedade.

Neste sentido, Soares (2002) propõe uma distinção entre Alfabetização e Letramento, explicando que aprender simplesmente a ler e a escrever auxilia na redução dos índices de analfabetismo no Brasil, mas não garante o desenvolvimento de um sujeito capaz de promover o desenvolvimento social, cultural, econômico e político do país, porque tais ações dependem de uma compreensão dos textos (sobretudo, da vida), que pode motivar um engajamento social. É preciso, por exemplo, mais que estabelecimentos de correspondência entre grafemas e fonemas, é mister cultivar e exercer diferentes práticas sociais que utilizam a leitura e a escrita.

As pessoas se alfabetizam, aprendem a ler e a escrever, mas não necessariamente incorporam a prática da leitura e da escrita, não necessariamente adquirem competência para usar a leitura e a escrita, para envolver-se com as práticas sociais de escrita: não leem livros, jornais, revistas, não sabem preencher um formulário, sentem dificuldade para escrever um simples telegrama, uma carta, não conseguem encontrar informações num catálogo telefônico, num contrato de trabalho, numa conta de luz, numa bula de remédio (SOARES, 2002, p. 45-46).

Embora proponha a distinção entre Alfabetização ("ação de ensinar/aprender a ler e a escrever", p.47) e Letramento ("estado ou condição de quem não apenas sabe ler e escrever, mas cultiva e exerce as práticas sociais que usam a escrita", p.47), Soares (2002) defende que alfabetizar e letrar não podem se separar, pois o ideal seria "alfabetizar letrando", isto é, garantir que a aprendizagem da leitura e a da escrita aconteçam no contexto de práticas sociais de leitura e escrita, de forma que o sujeito se tornasse, ao mesmo tempo, "alfabetizado e letrado".

Se a Alfabetização e o Letramento devem acontecer juntos, principalmente nos primeiros anos de escolaridade, é certo também que chegará um momento em que o indivíduo já terá aprendido a ler e a escrever, portanto, estará alfabetizado. Por outro lado, o letramento não se 
mostra como uma etapa finita, haja vista a constante criação de novos textos que circulam socialmente e as diferentes necessidades de atuação social, ou seja, embora o sujeito saiba ler e escrever e tenha determinado nível de letramento, sua vivência permitirá novas aprendizagens referentes à leitura e à escrita, portanto, seu nível de letramento tende a se desenvolver ou a iniciar uma nova fase, dadas as variantes encontradas nas distintas esferas sociais. Por exemplo: um sujeito adulto que já esteja alfabetizado e tenha certo nível de letramento na área da saúde pode se deparar com uma área totalmente nova em sua vida e "iniciar" seu cultivo e exercício das práticas de leitura e de escrita na nova área, segundo diferentes contextos sociais e culturais. Em outros termos, esse sujeito pode iniciar estudos musicais na maturidade, assim, entrará em contato com novos textos, como as partituras; entrará em contato também com a linguagem musical, com os conceitos de ritmo, melodia e harmonia, terá, portanto, de aprender a ler e a escrever novos textos.

O ensino de leitura não é uma atividade espontânea, tampouco aleatória. Segundo Kleiman (1998), a escolha do gênero de texto a ser trabalhado e a construção da sequência das ações a serem realizadas na sala de aula precisam de intencionalidade e planejamento, a fim de que cumpram o objetivo de desenvolver nos alunos a capacidade de entender, sintetizar o que leem e interagir socialmente com os textos.

O caminho indicado por pesquisadores para o desenvolvimento de leitores e escritores competentes na escola baseia-se na sistematização das atividades de leitura e escrita. Soares (2003) afirma que este processo de sistematização ou escolarização é necessário para organizar o trabalho educativo e inevitável na escola, cuja essência sustenta-se em procedimentos formalizados e organizados em categorias.

Não há como ter escola sem ter escolarização de conhecimentos, saberes, artes: o surgimento da escola está indissociavelmente ligado à constituição de "saberes escolares", que se corporificam e se formalizam em currículos, matérias e disciplinas, programas, metodologias, tudo isso exigido pela invenção, responsável pela criação da escola, de um espaço de ensino e de um tempo de aprendizagem. (SOARES, 2003. p. 20)

A sistematização de atividades de leitura e escrita na escola, de acordo com Lerner (2002, p. 33) é um desafio, visto que existe um "abismo que separa a prática escolar da prática social da leitura e da escrita". Desde as séries iniciais, a escola trabalha com uma "versão escolar" de leitura e de escrita bem diferentes do que as crianças e adultos terão de usar na vida fora da escola.

A autora aponta que, em algum momento, a transposição didática da leitura e da escrita na escola distanciou-se muito da realidade de leitura e escrita da sociedade. É evidente que a necessidade de ensinar o conhecimento leva a modificá-lo, a didatizá-lo; no entanto, com o passar do tempo, a escola criou seu jeito próprio de definir e trabalhar com leitura e escrita, assim, 
distanciou-se bastante do objeto original. A escola passou a fragmentar a leitura e a escrita, chegando ao ponto de distinguir entre leitura mecânica e leitura compreensiva.

Visto que a leitura e a escrita tornam-se objetos de ensino, é importante encontrar possibilidades de realizar a transposição didática sem desprezar o dinamismo da linguagem e a reflexão sobre os usos sociais da língua e dos textos.

A transposição didática é inevitável, mas deve ser rigorosamente controlada. É inevitável porque o propósito da escola é comunicar o saber, porque a intenção de ensino faz com que o objeto não possa aparecer exatamente da mesma forma, nem ser utilizado da mesma maneira que é utilizado quando essa intenção não existe [...]. Como o objetivo final do ensino é que o aluno possa fazer funcionar o aprendido fora da escola, em situações que já não serão didáticas, será necessário manter uma vigilância epistemológica que garanta uma semelhança fundamental entre o que se ensina e o objeto ou prática social que se pretende que os alunos aprendam (LERNER, 2002, p. 35).

No trabalho docente de sistematização do ensino da leitura e da escrita, torna-se essencial definir a estratégia de ensino e de aprendizagem. Evidentemente, o ato de planejar o ensino requer definição de objetivos de aprendizagem, no entanto, alcançá-los requer condições para que os alunos desenvolvam o conhecimento esperado.

Diante dessa abordagem do Letramento, escolhida pelos materiais do PNAIC, o polo de Presidente Prudente optou por complementar as ações com um estudo sistematizado das Estratégias de Leitura, com base nas pesquisas de Girotto e Souza (2010). O curso enfatizou a formação do professor leitor como sujeito que usa as Estratégias de Leitura em seu cotidiano e também faz reflexões metacognitivas, a fim de que possa intervir eficientemente sobre o processo de ensino e de aprendizagem da leitura nos anos iniciais de escolaridade. Foram realizadas atividades com as Estratégias de Leitura, abordando as seguintes etapas do processo de compreensão textual: "conexões, inferência, visualização, questionamento, sumarização e síntese" (GIROTTO e SOUZA, 2010, p. 47).

Para isso, foram desencadeadas as seguintes ações: 1. Os orientadores de estudo receberam com antecedência um e-mail no qual eram convidados a ler a obra que trata das Estratégias de Leitura. 2. Durante o encontro presencial, os orientadores de estudo socializaram as aprendizagens que tinham construído ao longo das leituras e das práticas de trabalho nas escolas, estudaram os principais conceitos e as etapas que compõem as Estratégias de Leitura. 3. Colocaram em prática as Estratégias, com a ajuda do formador responsável, pois leram diferentes textos. 4. Estudaram o material do PNAIC, que apresenta outros exemplos de trabalho com a leitura e debateram sobre as principais dificuldades de realização de atividades de leitura na escola, propondo maneiras de como incentivar os professores na aplicação das Estratégias de Leitura. 
Para que fiquem evidentes as etapas das Estratégias de Leitura trabalhadas no encontro presencial, cabe apresentar uma síntese das mesmas:

De acordo com Girotto e Souza (2010, p.50) a compreensão de um texto não se dá apenas no final da leitura, mas também durante a leitura. Assim, as aulas de leitura podem, intencionalmente, levar o aluno a pensar, a estabelecer um processo metacognitivo a serviço da significação. Para que ocorra o entendimento de um texto, 4 condições são básicas no leitor: a) Seu conhecimento prévio e suas experiências; b) O reconhecimento das características do texto que está sendo lido; c) A identificação do contexto da leitura - por que este texto está sendo lido?; d) Uso das estratégias aplicadas à leitura.

Para as autoras, as estratégias são:

“Conexão" (GIROTTO e SOUZA, 2010, p. 66) - usar tudo o que se sabe para entender o texto lido - Há 3 tipos: a) texto-texto: relacionar eventos, ideias, informações do texto com outros textos já lidos; b) texto-leitor: relacionar eventos, ideias, informações do texto com vivências do leitor; c) texto-mundo: relacionar eventos, ideias, informações do texto com acontecimentos do mundo. Para tanto, é sempre necessário ativar o conhecimento prévio - levantar o que o leitor conhece sobre o tema, o gênero textual, o autor do texto;

"Visualização" (Ibidem, p. 83) - inferir significados através de imagens mentais, pensar, por exemplo, nas características das personagens, nas cores, nas formas etc;

"Questionamento" (Ibidem, p. 91) - perguntar ao texto em busca da descoberta de informações que estão no texto (questões magras) ou que podem ser compreendidas a partir do texto (questões gordas);

"Inferência" (Ibidem, p. 74) - questionar o que é lido para tirar conclusões, fazer previsões, antecipar ações, refletir sobre a leitura;

"Sumarização" (Ibidem, p. 92) - aprender a buscar a importância das informações no texto, buscar a essência do texto;

"Síntese" (Ibidem, p. 101) - resumir, recontar, parafrasear o texto, acrescentando também a visão particular sobre o que foi lido.

Durante o curso do PNAIC, a fim de estudar as Estratégias, para ativar o conhecimento prévio foram expostos alguns objetos dentro de uma caixa. Cada participante tinha de escolher um objeto e falar o que sabia sobre ele. Os objetos faziam parte do enredo de uma obra de literatura infantojuvenil, que seria lida pelo grupo, portanto ao comentar sobre os objetos, cada sujeito colocava em prática o seu conhecimento prévio. Além disso, o título da obra e o nome do autor 
foram apresentados, para que o levantamento de conhecimento dos leitores pudesse se direcionar para a obra que seria lida.

Quando a obra começou a ser lida, logo de início, havia a descrição do espaço da narrativa. Neste momento, apenas uma pessoa lia a história para as demais, que ficavam de olhos fechados. Depois da leitura de um trecho, o formador responsável parou a leitura e perguntou o que as pessoas "viram" e "sentiram" com a leitura: quais eram as cores, os tamanhos, os cheiros etc. Com a socialização, estava se confirmando a Estratégia de Visualização.

Além disso, quando cada pessoa falava sobre suas sensações, fazia referência a outros textos lidos, a experiências vividas e a fatos noticiados na televisão. Estavam se manifestando as Conexões - muito importantes para que o leitor atribua sentido ao que está buscando compreender.

À medida que a obra continuava a ser lida coletivamente, o formador responsável propôs algumas perguntas que retomavam o que tinha sido lido, questionava sobre as ações das personagens, propunham a compreensão das ações. Esta etapa é a dos Questionamentos, que ajudam a colocar ordem na história, a dar sentido às ações.

Algumas respostas, dadas às questões feitas pelo formador, pressupunham como a história iria terminar, ou o motivo de o narrador valorizar alguma informação, para justificar uma possível conclusão do texto - estavam se manifestando as Inferências.

Quando a história acabou, novos Questionamentos e Inferências foram feitos para construir uma ideia global do texto. Em seguida, os orientadores de estudo montaram um esquema hierarquizando as ações e personagens do texto, evidenciando o evento desencadeador do conflito, as personagens principais, as secundárias etc. Com isso, acontecia a Sumarização.

Por último, a Síntese aconteceu quando cada participante recontou a história em uma linguagem: imagens, reescrita etc.

Depois disso, os orientadores de estudo foram para seus municípios e trabalharam com os alfabetizadores. Quando regressaram a Presidente Prudente, iniciaram relatos de que a receptividade entre os professores, nas localidades, foi muito grande, porque a maioria deles viu nas etapas das Estratégias de Leitura condições de ensinar a ler, para que melhore o desempenho das crianças.

\section{Considerações finais}

O uso das Estratégias de Leitura e da Sequência Didática na formação continuada dos orientadores de estudo do PNAIC contribuiu muito para a ampliação do conceito de leitura e produção de texto que eles apresentavam, pois houve maior clareza quanto a atividades desde o $1^{\circ}$ ano do ensino fundamental. Os procedimentos das Estratégias de Leitura e as etapas da Sequência 
Didática serviram como norteadores das ações docentes, já que organizam o ensino e se moldam às necessidades formativas dos alunos. Dessa forma, superam o ensino fragmentado da gramática isolada e dão sentido à atividade de leitura e produção de texto na escola, aproveitando os saberes dos alunos e fazendo-os pensar na função social do gênero de texto que está em estudo.

A partir das reflexões construídas os orientadores de estudo perceberam que o desenvolvimento da capacidade de compreensão dos textos não é espontâneo nos sujeitos, mas fruto de intervenções pedagógicas intencionais e planejadas.

Os orientadores de estudo também indicaram a necessidade de prosseguir estudando sobre a Sequência Didática, uma vez que o procedimento foi aplicado em diferentes salas de aula pelos professores alfabetizadores e os resultados positivos puderam ser notados. A prática de uma professora do $3^{\circ}$ ano, com relação à produção de texto, foi reconstruída, oportunizando, pelo uso da Sequência Didática, condições de melhoria das aprendizagens dos alunos.

\section{Referências}

Brasil. Secretaria de Educação Básica. Diretoria de Apoio à Gestão Educacional. Pacto nacional pela alfabetização na idade certa: formação de professores no pacto nacional pela alfabetização na idade certa / Ministério da Educação, Secretaria de Educação Básica, Diretoria de Apoio à Gestão Educacional. -- Brasília : MEC, SEB, 2012. Materiais disponíveis em: http://pacto.mec.gov.br/opacto.

DOLZ, J.; NOVERRAZ, M.; SCHNEUWLY, B. Sequências didáticas para o oral e a escrita: apresentação de um procedimento. In: DOLZ, J.; SCHNEUWLY, B. (Orgs). Gêneros orais e escritos na escola. Tradução de Roxane Rojo e Glaís Sales Cordeiro. Campinas: Mercado de Letras, 2004, p. 21-39.

KLEIMAN, A. B. Modelos de letramento e as práticas de alfabetização na escola. In: KLEIMAN, A. B. (Org.) Os significados do letramento: uma nova perspectiva sobre a prática social da escrita. 7. reimp. Campinas - SP: Mercado de Letras, 2004.

KLEIMAN, A. Oficina de leitura: teoria e prática. 6.ed. Campinas: Pontes, 1998.

GIROTTO, C. G. G. S. e SOUZA, R. J. Estratégias de leitura: para ensinar alunos a compreender o que leem. GIROTTO, C. G. G. S.; SOUZA, R. J.; MENIN, A. M. C. S.; ARENA, D. B. Ler e compreender: estratégias de leitura. Campinas: Mercado de Letras, 2010, p. 45-114.

LERNER, D. Ler e escrever na escola: o real, o possível e o necessário. Porto Alegre: Artmed, 2002.

SOARES, M. Letramento: um tema em três gêneros. Belo Horizonte: Autêntica, 2002. 
SOARES, M. A escolarização da literatura infantil e juvenil. BRANDÃO, H. M. B.;

EVANGELISTA, A. A. M.; MACHADO, M. Z. V. A escolarização da leitura literária. 2. ed. Belo Horizonte: Autêntica, 2003. p. 17-48.

Recebido em: 31.07 .2014

Aceito em: 24.10.2016 